\title{
Research on the Innovation Path of English Teaching in the New Media Era
}

\author{
Xiuhuan Ma \\ College of International Exchange, Liaoning University of International Business and Economics, Dalian, \\ 116052, China \\ 365556037@qq.com
}

Keywords: new media era; English teaching; teaching reform; reform contents; innovation path

\begin{abstract}
The new media technology with the Internet as the core has changed people's work, study and life. The traditional teaching mode has been impacted. English teaching must also conform to the trend of the era and meet the challenges from new media. Guided by the basic theory, this paper points out the shortcomings of traditional English teaching mode, analyzes the influence of new media on English teaching, and combines the main characteristics of new media, proposes the innovative path of English teaching in the new media era, and provides support for English teaching reform. The research results of this paper can make up for the shortcomings of traditional English teaching, cultivate students' self-learning ability, promote the formation of individualized learning methods, continuously improve the quality of English teaching, and meet the needs of English talents for economic and social development.
\end{abstract}

\section{Introduction}

The new media is based on modern digital information technology, using computer networks, wireless communication networks and satellites as channels, based on wired and wireless transmission modes, providing information services to users through mobile phones, computers and digital TV terminals. . The new media is mainly presented in the form of Internet media, mobile media and digital broadcast television. Today, with the rapid development of the Internet, new media has moved from the edge to the mainstream. Broadcasting is a new medium in relation to newspapers, television is a new medium in relation to broadcasting, and television is a new medium in relation to television. Science and technology are developing, and the form of media is also developing. From the process of media occurrence and development, it can be seen that new media is constantly changing along with the occurrence and development of the media.

One of the purposes of English teaching reform is to promote the formation of individualized learning methods for students and the development of independent learning ability. New media provides new solutions for English teaching reform. In the new media era, students should be able to choose their own learning materials and learning methods, gain guidance on learning strategies, and gradually improve their ability to learn independently. In the new media era, based on network technology and supplemented by the traditional teaching mode, time and place for students to learn is not limited, and the learning mode is developed towards independently and individuality. In the new media era, from teacher-centered, simple teaching of language knowledge and skills to student-centered, both language knowledge and skills, more emphasis on the development of language practical application ability and independent learning ability. As an English teacher, new media must be widely used in English teaching, advancing with the times, pioneering and innovating, continuously improving the quality of English teaching, and meeting the needs of the society for English talents.

\section{Main Features of New Media}

Compared to traditional media, new media has the following main features:

(1) Digitization and convenience. Digitization is the foundation of digital computers. It builds databases in the form of binary code and builds a virtual world that stores large amount of 
information. Digitalization has brought tremendous changes to people's social life. The new media is supported by modern digital information technology and appears in the form of network and mobile. It is especially convenient and quick to obtain information and browse information. Terminals such as computers and mobile phones can connect to the Internet anytime and anywhere through technologies such as mobile communication, enjoy information services, and extract necessary information from the virtual world. Breaking through the time and space constraints of information transmission, providing people with a large amount of information resource.

(2) Interactivity and timeliness. The new media has realized two-way and even multi-directional communication between the media and the audience, so that the audience has the right to speak and can fully participate in the exchange. Through various forms of new media, people can fully enjoy various network resources and share their information resources in real time. The advantages of new media's interactivity and timeliness are fully utilized by developers in software development and are favored by users. From traditional media to new media, the audience has also changed from passive acceptance to active participation, breaking the dilemma of one-way communication and realizing the multi-directional communication of information. Everyone can be the publisher, disseminator and receiver of information.

(3) Individuation and equality. The new media has changed the passive position of the audience in information dissemination, and established a diversified interactive communication relationship between the media and the audience, between the audience and the audience. Through the new media, the identity of the information disseminator and the receiver is no longer certain, and everyone can become a disseminator or a receiver, and the status between the two is equal. The new media realizes the two-way interactive communication between the disseminator and the receiver. When the disseminator publishes the information on the Internet, the receiver can respond and supplement it according to the individual's ideas and interests. Feedback to the original disseminator in a timely manner can also be forwarded to other people to achieve two-way interaction and multi-directional interaction of information.

\section{Related Theoretical Basic Research}

The theoretical basis for the application of new media to English teaching includes the following four aspects:

(1) Multiple intelligence theory. Harvard University psychologist Howard Gardner puts forward the basic idea: when developing the intelligence of students in all aspects, school must pay attention to each student's intelligence in one or two aspects; when the students fail in other aspects, don't catch up with the progress, don't punish the students for this. The theory of multiple intelligence encourages teachers to pay more attention to the different intelligence of students. In the classroom, the multi-intelligent teaching mode is used to help students find their own intellectual advantages in the process of learning, so that students have a sense of accomplishment in acquiring knowledge and promote students to learn English to promote the development of multiple intelligence.

(2) Constructivist theory. Students gain new knowledge by using certain supplementary conditions, with the support of the original knowledge, through active exploration, comprehension, experience and communication, thus consciously constructing the activity process of the knowledge context. Students are the main part of teaching activities. Students filtrate and organize the information they receive to build their own knowledge systems. Communication and coordination between teachers and students is also very important for knowledge building. The new media provides a convenient way for communication and interaction, creating an ideal learning environment for students, which is conducive to stimulating students' potential and enriching students' understanding of knowledge, thus promoting their knowledge construction.

(3) Self-learning theory. The theory of self-learning is based on humanistic psychology. In the process of learning, students are the main part, and teachers are only promoters. It is necessary to pay attention to the needs, emotions and willingness of learners in the learning process. It is a kind of practical learning, a life that integrates learning and experience, and fully mobilizes students' enthusiasm for learning. Create good environment for learners to perceive the world from their own 
perspective, achieve an understanding of the world, achieve the highest level of self-realization. The theory of self-learning originated from the concept of humanistic learning and is the most direct embodiment of humanistic thinking.

(4) Informal learning theory. Informal learning refers to what happens in informal learning situations such as work, life, and social interaction. Knowledge is transmitted through non-teaching social interactions, which are initiated, self-regulated, and self-responsible by learners. Informal learning is a learning behavior spontaneously produced by learners. Individuals regulate and control the learning process. The learning initiative is in the hands of the learners. It can fully exert the individual's subjective initiative and choose to have a purposeful learning. The new media creates conditions for students to carry out informal learning and provides the sufficient basis for students to carry out informal learning.

\section{Shortcomings of Traditional English Teaching Mode}

There are many shortcomings in the traditional English teaching mode, which are highlighted in the following two aspects:

(1) Teaching and information transferring methods are single. The traditional English teaching adopts the perfusion or speech mode. The teacher mainly teaches in the classroom. The teaching content is based on the knowledge content of the textbook. The teaching activity information flows in a single or one-direction mode. The constant teaching time and the number of students in traditional classroom teaching limit the interaction between teachers and students. Teachers and professors give students the knowledge information that meets the content of the teaching materials and the needs of the examination, but it is not in line with the goal of cultivating students' English application ability. It is conducive to the development of students' independent learning ability and the improvement of comprehensive cultural accomplishment.

(2) Individual differences in students cannot be considered. Traditional English teaching can not take into account the individual differences of students, can not carry out differential education, and can not stimulate students' initiative. Students must always be consistent with the progress of teaching in order to effectively absorb the teaching content. Students do not choose the autonomy of learning content, learning styles and learning progress. Each student's ability to comprehend and understand knowledge is different. Students' ability to digest and absorb knowledge is also different. The traditional teaching model cannot solve the problem of student differentiation, which limits the initiative and creativity of students and affects the learning effect.

\section{Influence of New Media on English Teaching}

The new media has brought about tremendous changes in teaching work. The influences on English teaching is mainly reflected in the following four aspects:

(1) Promoted the transformation of teaching modes. Traditional teaching mode English learning mainly depends on textbooks and teachers. The textbooks are written from the perspective of English culture. The content is limited and cannot keep up with the development of the time, which constraints the development of students' ability. The teacher is the leading actor of the classroom, the students are in the passive state, and the enthusiasm for learning is not high, which is not conducive to the cultivation of communicative ability. The new media has broadened the content of English teaching, and students have more oral expression and cross-cultural communication opportunities. Teachers can use the new media to guide students, students can access more learning resources, develop students' ability in a targeted manner, and improve the quality of English teaching.

(2) Promoted the transformation of learning style. In the traditional teaching mode, students mainly concentrate on learning in classrooms and libraries. They are constricted in various conditions and are in a passive learning state, which is not conducive to the cultivation of English application ability. The new media has broken the time and space restrictions of traditional teaching and broadened the channels of information acceptance. Students can use the Internet to search for 
relevant resources, learning is no longer limited to books, but also broaden their horizons. With a variety of English learning software and tools, we can improve the practical application of English. At the same time, under the new media environment, students can learn independently, choose the materials they like, and cultivate their personality development.

(3) Extended the content of English teaching. The further optimization of teaching content and the effective extension of teaching resources have become effective ways to improve the quality of students. In the new media environment, the collection, screening and application of extracurricular teaching materials are carried out to realize the extension of teaching content. Through computer technology search function, search for teaching materials combined with textbook content and outline requirements, including English anime, movies and songs. Make full use of the established corpus, extend the teaching content through the necessary reading and the purpose of reading, guide students to read independently, broaden students' horizons, improve reading comprehension and information processing ability.

(4) Promoted the construction of the new relationship between teachers and students. The new media has an important impact on the relationship between teachers and students. First, in the field of education and teaching, the wide application of new media, communication between teachers and students through WeChat and Weibo, avoiding the problem of traditional face-to-face communication, easy to form the teacher role like a friend. Second, in terms of emotional attitudes, the use of new media is easy to form a harmonious teacher-student relationship, improve mutual satisfaction and happiness, students are more willing to accept teacher guidance, promote the formation of students' world outlook, life outlook and value outlook; teachers are also more willing to communicate with students, helping to better complete teaching tasks.

\section{Innovation Path of English Teaching in the New Media Era}

In order to overcome the shortcomings of the traditional English teaching mode and give full play to the advantages of new media in English teaching, referring to the relevant literature, the innovative path of English teaching in the new media era proposed in this paper is as follows:

(1) Use the new media to establish the English learning communication platform. The applicability of English is strong. Traditional English teaching and English communication are mainly limited to the classroom. Once separated from the classroom, daily communication will become a mother tongue, and the opportunities and time for English communication are very few. New media technology creates conditions for cultivating students' English communication skills, and with the support of new media technologies, creates an English learning exchange platform to enhance students' English proficiency. English teachers can continually update teaching materials, supplement learning resources, record courses for teaching content, and teach in real time on the Internet. Teachers should be good at using tools such as WeChat and QQ to build an English learning group and encourage students to communicate in English in groups. You can use both typewriting and voice to communicate and improve your English. You can also use the new media technology to build a communication platform for Chinese and foreign students, provide support for students to communicate with foreigners, and improve their intercultural communication skills.

(2) Strengthen students' new media literacy education. Media literacy is the ability to recognize, judge, and use the media's attitudes and abilities, including the ability to choose, understand, question, evaluate, create, and respond to media. First, attach importance to new media knowledge education. Increase the content of new media literacy education, explain to students the relevant knowledge of the type, characteristics and use, and use communication, information science, media ethics and related legal knowledge as an supplementary to form a new media literacy theory, and join the performance appraisal. Second, develop the ability to use new media correctly. Students receive information through a variety of new media such as QQ, MSN, WeChat, Weibo, Forum and Community, allowing free exchange and expression of ideas, enhancing their position and role in the new media environment, and cultivating new media use capabilities. Third, develop students' self-education ability. Fully understand the importance of media literacy, train students to consciously carry out self-cognition, self-regulation and self-management according to certain 
norms, stimulate the initiative of self-education, and play the main role of self-education.

(3) Promote the application of micro video in English teaching. In the new media environment, interactive media provides the best interaction for English teaching innovation. Integrated online media provides the best teaching innovation for English teaching, while micro video provides a full range of experimental field as innovation for English teaching. Due to the unlimited length of micro video and the low production threshold, students can use the hand-held terminal with video function to create English short drama or English video creative based on any scene. This all-round English language application is convenience. The convenience brought by technology also provides students with the process of learning, playing and creating from the simple learning of the language to the use of what they have learned. Compared with other English teaching methods, micro video not only provides students with an experience field for applying English language, but also provides opportunities for improving information technology.

(4) Strengthen the supervision over the dissemination of new media. The high speed of information and the diversified forms of communication of new media information bring users a convenient experience, and effective supervision becomes a new problem. First, create good network culture. Use firewall technology to filtrate spam and stop unethical disruptive behavior. Use password setting and encryption technology to prevent important information from being tampered, copied and contaminated, and reduce the negative impact on students. Second, strengthen campus network public opinion management. Prevent the infringement of bad information, master the initiative of network public opinion, resolutely block and delete harmful information, explain doubts and resolve conflicts, form positive and mainstream public opinion, create a good public opinion environment, and ensure the healthy and orderly development of school network information services. Third, strengthen the construction of school culture. Students face many problems such as academic, emotion, communication and employment, and the new media will have a negative impact on the spread of these issues. Carry out a variety of cultural activities, persuade students' psychological problems, create the good campus culture atmosphere, and avoid the negative effects of new media, such as loneliness, lack of spiritual poverty and thought laziness.

\section{References}

[1] T. N. Chen, "A Probe into the Integration of New Media into College English Teaching," Journal of Heilongjiang College of Education, vol. 37, no. 7, pp. 136-138, 2018.

[2] W. Zhang, "Research on college English teaching methods under the background of new media," English Square, vol. 8, no. 10, pp. 54-56, 2018.

[3] S. S. He, "The application of multiple intelligence theory in college English teaching," Journal of Chizhou University, vol. 32, no. 3, pp. 145-147, 2018.

[4] H. H. Li, H. P. Li, "Teaching reform and practice of college English courses in colleges and universities in the era of new media," Information Recording Materials, vol. 19, no. 9, pp. 200-201, 2018.

[5] W. Liu, "Reform and practice of college English teaching from the perspective of new media," Education Modernization, vol. 5, no. 25, pp. 75-76, 2018. 